\title{
Candida Bezoars in Adults: Determining Optimal Management
}

\author{
Matthew A. Rohloff, DO, Jaschar Shakuri-Rad, DO, and Alexander P. Dehaan, DO
}

\begin{abstract}
Fungal bezoars, or fungal balls, are rare pathologic consequences of funguria in immunocompromised patients. Current treatment recommendations are based on expert opinion and low level evidence. We present a case of a Candida glabrata bezoar that was effectively treated with percutaneous amphotericin B instillations. A subsequent literature review is presented to assess the available case reports and treatment outcomes of Candida spp. bezoars in adults.
\end{abstract}

Keywords: fungal bezoar, fungal ball, Candida funguria, percutaneous nephrostomy, amphotericin B instillations

\section{Introduction}

T HERE ARE A SCATTER of case reports of fungal bezoars in the adult urologic literature and even fewer caused by Candida glabrata. As a result of the paucity of data, there are no guidelines outlining a treatment algorithm for management of Candida bezoars. The Infectious Disease Society of America 2016 guidelines recommend surgical removal, antifungal treatment, or irrigation of amphotericin B through a nephrostomy tube. These recommendations are based on low-quality evidence. ${ }^{1}$ The purpose of this case report is to discuss a patient with a $C$. glabrata bezoar who was effectively managed with intravenous antifungals and percutaneous nephrostomy tube instillations of amphotericin B.

\section{Case Report}

A 56-year-old female with a medical history significant for type 2 diabetes mellitus, chronic pancreatitis, and alcoholism was admitted to our institution in October 2016 with the chief complaint of abdominal distention and generalized malaise. Review of systems was pertinent for mid-back pain that radiated to her bilateral lower extremities, dysuria, incomplete voiding, and urinary urgency. The patient did not have any urologic history.

Laboratories were significant for leukocytosis of $11.0 \mathrm{~K} / \mu \mathrm{L}$, creatinine of $2.275 \mathrm{cc} / \mathrm{dL}, \mathrm{GFR}$ of $22 \mathrm{cc} / \mathrm{min} / 1.73 \mathrm{~m}^{2}$, and a urinalysis that showed large RBCs, WBCs, and many yeast cells. Noncontrast $\mathrm{CT}$ of abdomen and pelvis was obtained that showed multiple bilateral nonobstructing renal stones, but no discrete intrarenal lesion (Fig. 1). The patient was found to have a postvoid residual $>999 \mathrm{cc}$ and was straight catheterized for $3000 \mathrm{cc}$ of urine.

Blood and urine cultures yielded $C$. glabrata. A fungal ball remained high on the differential diagnosis, and despite an equivocal CT scan, a renal ultrasonography was obtained. The left kidney showed a $7 \mathrm{~mm}$ echogenic structure resembling a fungal ball (Fig. 2). The infectious disease team placed the patient on oral micafungin and IV diflucan. Systemic amphotericin B was avoided to prevent exacerbation of kidney injury in a patient with compromised renal function.

The patient also underwent percutaneous nephrostomy tube placement by interventional radiology to facilitate amphotericin B irrigations. She continued with daily $50 \mathrm{mg}$ instillations of amphotericin B in $500 \mathrm{cc}$ of water for 6 days until resolution of sepsis. The patient continued to improve and it was determined that further operative intervention was unnecessary. She remained on IV micafungin and diflucan for a total of 14 days. On discharge, blood and urine cultures showed no fungal growth and the patient's leukocytosis and acute kidney injury had completely resolved. The patient was last seen 3 months posthospitalization and remains asymptomatic.

Metro Health Hospital-University of Michigan Health, Wyoming, Michigan.

(C) Matthew A. Rohloff et al. 2017; Published by Mary Ann Liebert, Inc. This Open Access article is distributed under the terms of the Creative Commons License (http://creativecommons.org/licenses/by/4.0), which permits unrestricted use, distribution, and reproduction in any medium, provided the original work is properly credited. 


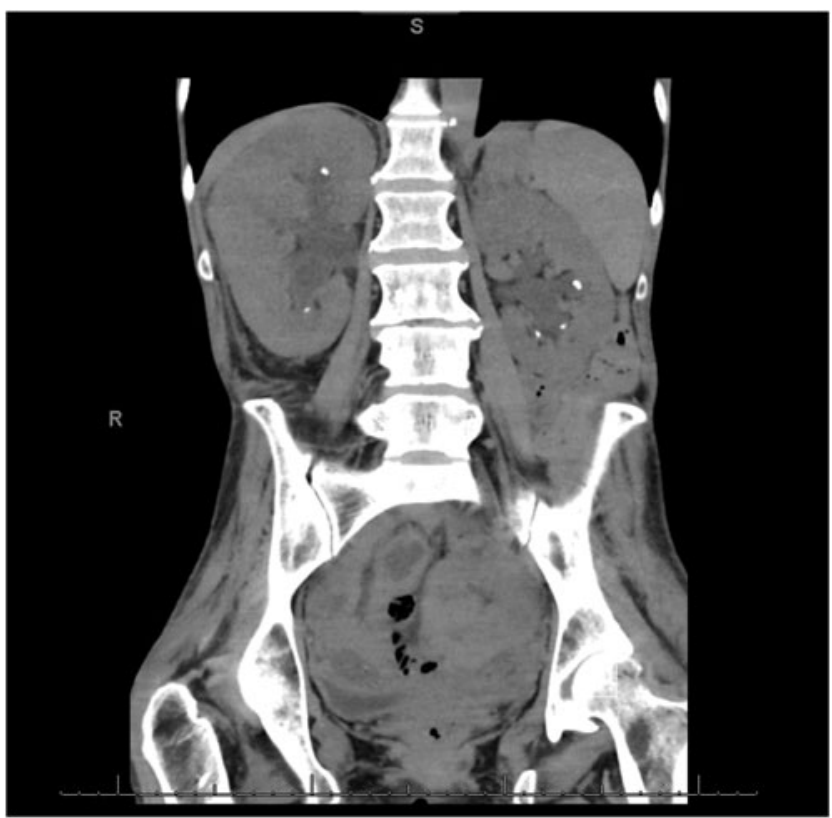

FIG. 1. CT of abdomen and pelvis. Multiple bilateral renal stones measuring between 1 and $4 \mathrm{~mm}$. Bilateral pelvocaliectasis. No discrete renal lesions although renal fungal ball cannot be excluded.

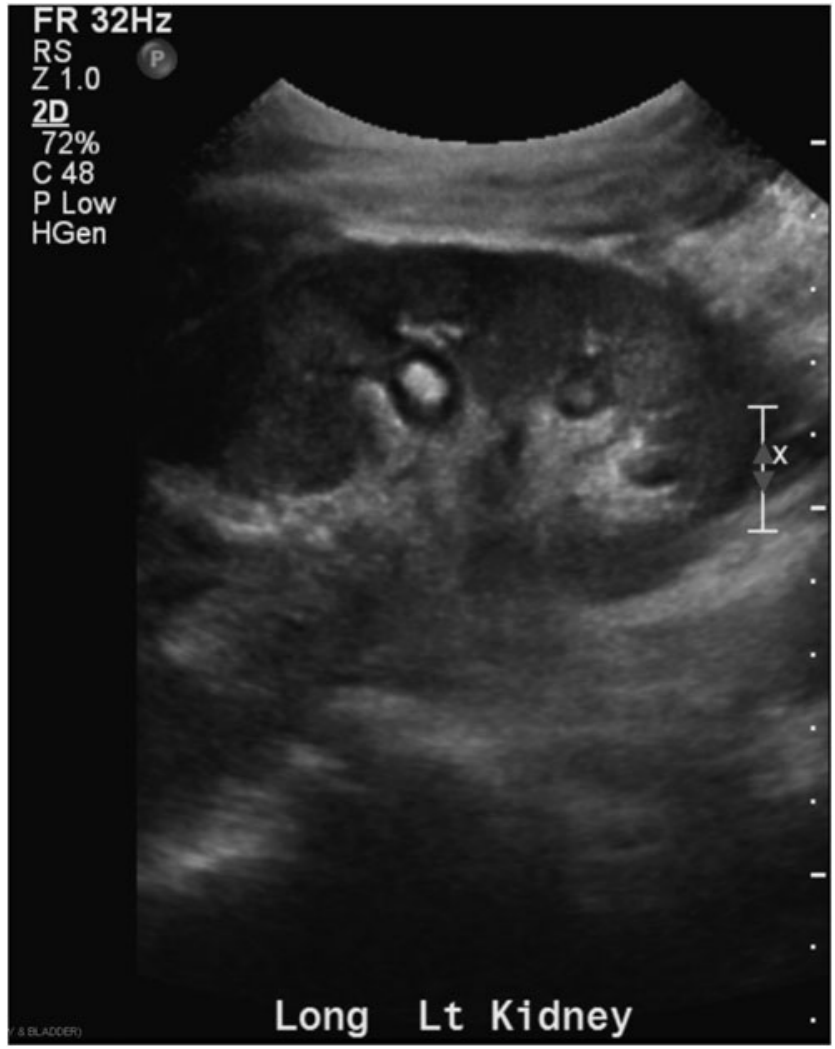

FIG. 2. Renal ultrasonography. Seven millimeter, left sided interpolar nonshadowing hyperechoic foci in the renal collecting system.

\section{Discussion and Literature Review}

For the past decade, there has been a $300 \%$ increase in the prevalence of opportunistic fungal urinary tract infections (UTIs). ${ }^{2,3}$ It is estimated that $5 \%$ of urine cultures yield Candida spp. and $26.5 \%$ of UTIs with indwelling Foley catheters are inoculated with fungi. ${ }^{2}$ Although asymptomatic funguria requires no treatment, symptomatic funguria in the setting of underlying immunosuppression can lead to significant pathology analysis. This is further exacerbated by patients inoculated with $C$. glabrata, as they are often resistant to azole antifungal agents and require systemic or local amphotericin B irrigation. 4

Historically, treatment of fungal bezoars has been based on clinical presentation and physician discretion. Recently, the Infectious Disease Society of America 2016 guidelines were presented to help assist in management decisions. The recommendation to utilize surgical removal has been described as "central to effective treatment," but is based on two small case reports and low-quality evidence. ${ }^{1}$ In an attempt to better categorize treatment modalities and outcomes, case reports involving renal candidiasis and fungal balls in adults were obtained utilizing the database from National Center for Biotechnology Information (NCBI) and U.S. National Library of Medicine (NLM) (Table 1).

Comprehensive literature review of 15 case reports yielded patients who were effectively treated both operatively and nonoperatively. Seven patients of the 15 operative case reports chose operative removal, which consisted of two nephrectomies, one cystotomy, one pyelolithotomy, and three endoscopic retrievals. Of the seven reported operative cases, six patients were discharged home in stable condition and one died before discharge. The other eight cases were treated with conservative approaches utilizing local antifungals, systemic antifungals, or spontaneous expulsion. Seven of the eight cases were discharged to home in stable condition and the outcome of one of the cases was unreported.

Although strong evidence-based suggestions on superior therapy cannot be obtained from a few case reports, it is evident that both modalities have had advantageous outcomes. Operative intervention, although potentially curative, is not without its own inherent risks. Based on our patient, and the findings of seven other medically managed cases, it is reasonable to suggest that medical management of fungal bezoars is not inferior to operative intervention. Optimal treatment regimens for individual patients are ultimately based on the discretion of the treating physician. Figure 3 shows an algorithm to further assist with the treatment of Candida bezoars.

\section{Conclusions}

Although Candida bezoars are extremely rare in the urologic literature, it is imperative that recommendations based on quality data are obtained to optimize treatment. The presented case is a 56-year-old female with a $C$. glabrata bezoar who was effectively treated with systemic antifungals and percutaneous amphotericin B instillations. This case serves as a reminder that fungal bezoars can be managed without fungal ball extraction and still have advantageous outcomes. 


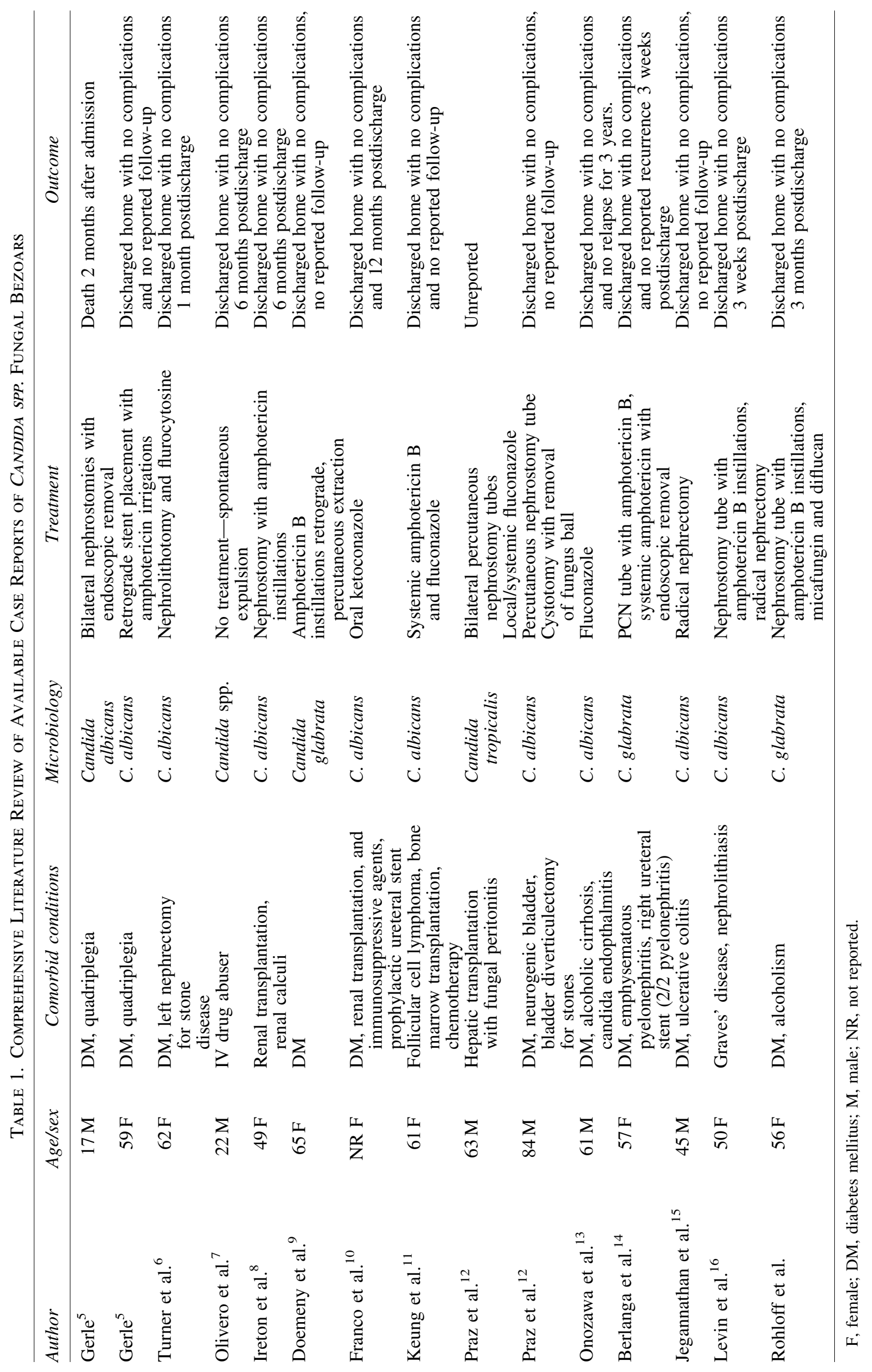


FIG. 3. Treatment algorithm for patients with Candida spp. fungal bezoars. Literature review shows that medical therapy is not inferior to surgical management. 1, dependent on physician discretion; PCN, percutaneous nephrostomy.

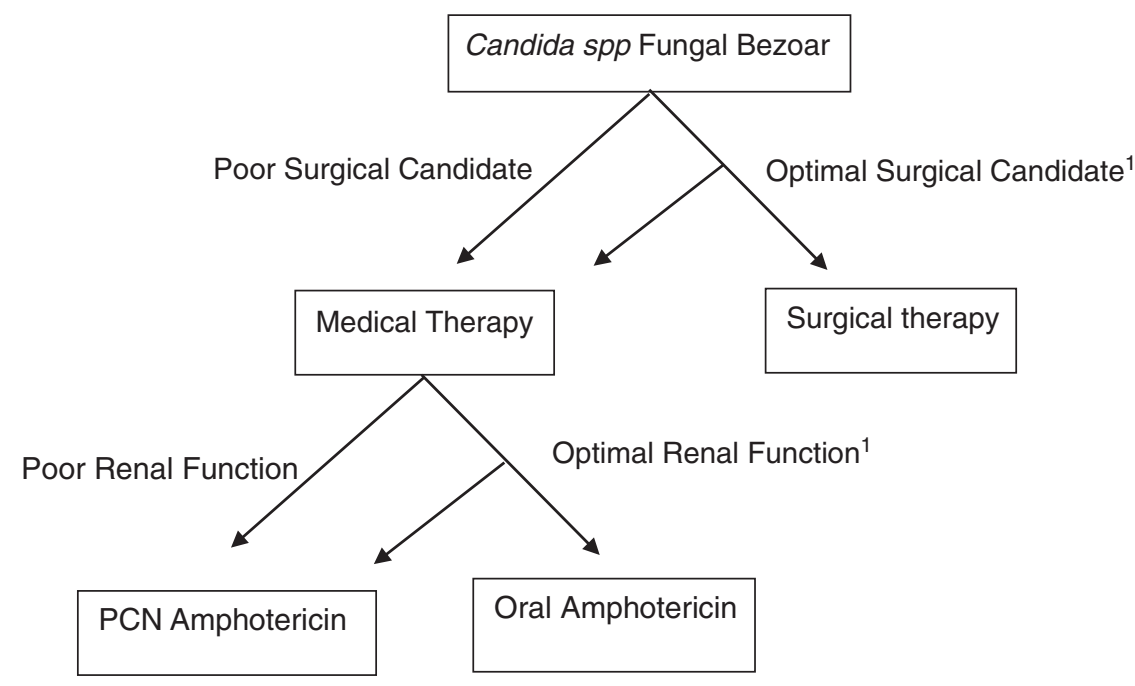

\section{Acknowledgment}

We appreciate the work and assistance of our librarian, Mary Loftis, for helping us obtain the case reports enclosed in this article.

\section{Author Disclosure Statement}

No competing financial interests exist.

\section{References}

1. Pappas PG, Kauggman CA, Andes DR, et al. Clinical practice guideline for the management of candidiasis: 2016 update by the Infectious Diseases Society of America. Clin Infect Dis 2016;62:e1-e50.

2. Platt R, Polk BF, Murdock B, et al. Risk factors for nosocomial urinary tract infection. Am J Epidemiol 1986;124: 977-985.

3. Kauffman CA. Candiduria. Clin Infect Dis 2005;41:371-376.

4. Kauffman CA, Vazquez JA, Sobel JD, et al. Prospective multicenter surveillance study of funguria in hospitalized patients. Clin Infect Dis 2000;30:14-18.

5. Gerle RD. Roentgenographic features of primary renal candidiasis. AJR Am J Roentgenol 1973;119:731-738.

6. Turner R, Grigsby TH, Enright JR, et al. Anuria secondary to mechanical obstruction caused by a Candida fungus ball. J Urol 1973;109:938-940.

7. Olivero J, Bacque F, Carlton CE Jr, Eknoyan G. Renal complications of drug addiction. Urology 1976;8:526-531.

8. Ireton R, Krieger JN, Rudd TG, Marchioro TL. Percutaneous endoscopic treatment of fungus ball obstruction in a renal allograft. Transplantation 1985;39:453-454.

9. Doemeny J, Banner MP, Shapiro MJ, et al. Percutaneous extraction of renal fungus ball. AJR Am J Roentgenol 1988; 150:1331-1332.

10. Franco A, Prados MC, Perdiguero M, Olivares J. Fungus ball: a cause of early obstructive uropathy in renal transplantation. Clin Nephrol 1992;38:294.

11. Keung Y, Khan A, Skinner E, Douer D. Localized renal pelvic fungal ball in a patient undergoing bone marrow transplantation. Acta Haematol 1993;89:160-162.

12. Praz V, Burruni R, Meid F, et al. Fungus ball in the urinary tract: A rare entity. Can Urol Assoc J 2014;8:118-120.
13. Onozawa K, Miyake N, Iwasaki N, et al. A case of Candida albicans fungus balls in the urinary tract appeared during the course of antifungal treatment for Candida endopthalmitis. J Infect Chemother 2015;21:687-690.

14. Berlanga G, Machen GL, Lowry PS, Brust KB. Management of renal fungal bezoar caused by multidrug-resistant Candida glabrata. Proc (Bayl Univ Med Cent) 2016; 29:416-417.

15. Jegannathan D, Ramanathan K. Renal fungal ball-two case reports and review of literature. BJR Case Rep 2016;2:1-4.

16. Levin DL, Zimmerman AL, Ferder LF. Acute renal failure secondary to ureteral fungus ball obstruction in a patient with reversible deficient cell-mediated immunity. Clin Nephrol 1975;4:202-210.

Address correspondence to: Matthew A. Rohloff, DO

Metro Health Hospital-University of Michigan Health 5900 Byron Center Ave SW

Wyoming, MI 49519

E-mail: matthew.rohloff@metrohealth.net

$\begin{aligned} & \quad \text { Abbreviations Used } \\ & \text { CT }=\text { computed tomography } \\ & \text { DM }=\text { diabetes mellitus } \\ & \text { GFR }=\text { glomerular filtration rate } \\ & \text { IV }=\text { intravenous } \\ & \text { NCBI }=\text { National Center for Biotechnology Information } \\ & \text { NLM }=\text { U.S. National Library of Medicine } \\ & \text { NR }=\text { not reported } \\ & \text { UTI }=\text { urinary tract infection }\end{aligned}$

Cite this article as: Rohloff MA, Shakuri-Rad J, Dehaan AP (2017) Candida bezoars in adults: determining optimal management, Journal of Endourology Case Reports 3:1, 45-48, DOI: 10.1089/cren.2017.0021. 